\title{
SAFETY PROFILE OF CHLORAL SEDATION FOR MRI IN TERM AND PRETERM NEONATES
}

A. Finnemore, H. Toulmin, N. Merchant, T. Arichi, N. Tusor, D. Cox, A. Ederies, P. Nongena, C. Ko, R. Dias, A. Groves, D. Edwards

Imaging Sciences, Imperial College, London, UK

Background: Chloral hydrate is a widely used sedative for MRI scanning in the newborn. However some studies suggest that infants may have a relatively high risk of complications ${ }^{1}$. The aim of this study was to assess the adverse effects of sedation in a large cohort of neonates.

Method: Infants $>32$ weeks gestation undergoing brain MRI at our institution are sedated and monitored according to strict protocols. Casenotes of infants who underwent MRI scanning from 2008-2010 were retrospectively reviewed. Infant demographics were recorded, along with sedation dose, comorbidities, time to discharge and side effects of sedation including oxygen requirement and significant desaturation/apnoea.

Results: 411 infants (median gestation/weight at scan 42weeks/3500grams) were sedated with chloral hydrate(median dose $50 \mathrm{mg} / \mathrm{kg}$ ). 408(99.3\%) infants completed the scan. The overall complication rate was $5.1 \%(95 \%$ confidence limits $2.9-7.3 \%)$. Desaturation or additional O2 requirement occurred during MRI scan in 20 babies(4.9\%), but episodes were all short-lived and did not delay discharge home. 1 patient required overnight observation following an apnoeic episode post-MRI, but was discharged without complication the following day. There were no significant differences in gestational age $(p=0.16)$, corrected gestation at $\operatorname{scan}(\mathrm{p}=0.62)$, weight at $\operatorname{scan}(\mathrm{p}=0.19)$ or sedation $\operatorname{dose}(\mathrm{p}=0.29)$ between the affected and nonaffected groups. Lower birthweight was associated with fewer adverse events $(\mathrm{p}=0.03)$, presumably because higher birthweight babies were scanned following neurological insult.

Conclusion: When adhering to strict protocols and with adequate monitoring, chloral hydrate sedation for MRI scanning can be safely performed for both preterm and term infants.

1. Litman et al, Anaesthesia \& Analgesia 2010. 